This item was submitted to Loughborough's Research Repository by the author.

Items in Figshare are protected by copyright, with all rights reserved, unless otherwise indicated.

\title{
The implementation of Governance, Risk, and Compliance IS: adoption lifecycle and enterprise value
}

PLEASE CITE THE PUBLISHED VERSION

http://dx.doi.org/10.1080/10580530.2016.1220214

\section{PUBLISHER}

(C) Taylor \& Francis

\section{VERSION}

NA (Not Applicable or Unknown)

\section{PUBLISHER STATEMENT}

This work is made available according to the conditions of the Creative Commons Attribution-NonCommercialNoDerivatives 4.0 International (CC BY-NC-ND 4.0) licence. Full details of this licence are available at: https://creativecommons.org/licenses/by-nc-nd/4.0/

\section{LICENCE}

CC BY-NC-ND 4.0

\section{REPOSITORY RECORD}

Spanaki, Konstantina, and Anastasia Papazafeiropoulou. 2019. "The Implementation of Governance, Risk, and Compliance IS: Adoption Lifecycle and Enterprise Value”. figshare. https://hdl.handle.net/2134/24554. 


\title{
The Implementation of Governance Risk and Compliance Information Systems (GRC IS): Adoption Lifecycle and Enterprise Value
}

\author{
Konstantina Spanaki ${ }^{1}$, Anastasia Papazafeiropoulou ${ }^{2}$ \\ ${ }^{1}$ Department of Innovation and Entrepreneurship, Imperial College Business School, London, \\ $U K$ \\ ${ }^{2}$ Department of Computer Science, Brunel University, London, UK
}

\begin{abstract}
Governance, Risk and Compliance (GRC) has become an emerging field within the IS academic community. Motivated by this research direction, the study capitalizes on the theoretical background of Enterprise Systems (ES) and extends the focus on GRC systems' implementation (enterprise value and lifecycle). Building upon expert views on GRC IS implementation projects, the analysis indicates that the three value drivers of integration; optimization and information should be considered throughout the whole GRC IS implementation lifecycle.
\end{abstract}

Keywords: Governance, Risk and Compliance Information Systems (GRC IS); Adoption Lifecycle; Enterprise Value

Address correspondence to:

${ }^{1}$ Konstantina Spanaki, Department of Innovation and Entrepreneurship, Imperial College Business School, South Kensington Campus, SW7 2AZ, London, UK. Email: k.spanaki@imperial.ac.uk

${ }^{2}$ Anastasia Papazafeiropoulou, Department of Computer Science, Brunel University London, St. Johns Building,

UB8 3PH, Uxbridge, UK. Email: Anastasia.Papazafeiropoulou@brunel.ac.uk

\section{INTRODUCTION}

The acronym GRC is used to identify the Governance, Risk and Compliance area, consisting different aspects of these three principles. The GRC can be viewed by different research perspectives such as financial GRC, enterprise GRC or information systems GRC. The study builds upon an Enterprise System (ES) perspective of GRC and investigates its value in meeting business requirements.

Forced by legal and regulatory requirements related to the Sarbanes - Oxley Act of 2002 many organizations invest on risk and control functions of the IS, related with the GRC principles. The wide-ranging GRC impacts and responsibilities for governance expectations and compliance requirements resulted in the expansion of the GRC IS. Areas such as compliance, legal, internal auditing, and enterprise risk management (Frigo \& Anderson, 2009) triggered the creation of automated governance, risk and compliance (GRC) initiatives for the organization's risk and control improvement. Within the last few years, the increasingly complex regulatory environment has prompted organizations to focus heavily on issues of risks and controls (Leishman, Brouwers, \& Farineau, 2009). Based on the same KPMG report of 2009 (Leishman et al., 2009), organizations while trying to ensure they are getting business value from their compliance efforts, they try to make them more integrated and effective. For that reason recent business solutions introduce continuous control monitoring practices for the integration of the 
organizational efforts with regards to the GRC area. These GRC tools address multiple requirements efficiently and enable a single view of organizational risks and controls to mitigate enterprise risks. In general terms, we can define GRC Information Systems (GRC IS) as:

Integrated Enterprise Systems supporting holistically the risk, control and auditing functions of organizations related with the GRC compliance principles.

While enterprise systems (ES) implementation is a well-researched area, the implementation of GRC IS is not analyzed extensively within the GRC literature. Existing academic literature about GRC implementations indicates that researchers have more ground to cover in this field as a lot of aspects have not been extensively investigated yet (Gericke, Fill, Karagiannis, \& Winter, 2009; Papazafeiropoulou \& Spanaki, 2015). Existing literature on GRC indicates a gap regarding many aspects of the GRC implementation process and the value creation for organization (Spanaki \& Papazafeiropoulou, 2013). Following this motivation, the research focuses on getting insights to fill this gap.

The paper explores the GRC implementation experience and sheds light on the adoption lifecycles and the enterprise value and how these can provide a strategic advantage for the organizations. The study recognizes GRC IS as a fundamental business requirement and focuses on the need to further analyze the successful implementation of such IS. Therefore, the adoption lifecycles and the enterprise value of the GRC IS implementation process are further investigated.

For the purpose of this study, data were collected according to a field study of stakeholders with experience in GRC IS implementation projects worldwide. The data collection process took a 10-month period and followed a thematic methodology to analyze them. The research question motivating the study was

"How can we analyze the GRC IS adoption lifecycle and how this analysis can assist in achieving enterprise value through a successful GRC environment?"

The paper is structured as follows. First, the prior research on the GRC field is considered providing the motivation for researching the area of GRC implementation. Second, the theoretical background framing the GRC implementation is further explained presenting the two theoretical streams used (enterprise systems adoption lifecycle and enterprise value and success) and how these can be related and enhanced. Third, the methodological approach is described with a focus on the research design and the sampling strategy. Last, the interview data about the GRC lifecycle phases and the value drivers are presented as well as analysis and discussion about these data. The paper concludes with the future research agenda and the contribution.

\section{PRIOR RESEARCH ON GRC}

The explosion of information systems (IS) in the world of enterprises could be characterized as the most notable change throughout the history of business (Maurizio, Girolami, \& Jones, 2007). Maurizio et al (2007) consider enterprise system implementations as change initiatives, enabling organizational transformation and process redesign. Therefore, attention should be paid prior to the implementation of large enterprise solutions, as key considerations can ensure the implementation process success (Lee, 1998). The approaches described in software engineering or change management addressing the implementation of IS cannot be applied to GRC solutions without considering certain GRC specifics (Gericke et al., 2009). The complexity and cost of the GRC IS make their implementation strategy a very demanding one (Cangemi, 2008). For many organizations, GRC challenge was facilitated by manual ways, using people resources to monitor the performance (Cangemi, 2008). 
Another important characteristic of GRC tools is that this software can provide 'a singly companywide platform for control and compliance' (Cangemi, 2008), as reporting processes and compliance with regulatory requirements can be facilitated through GRC IS. This is feasible even when multiple ERP systems are in place, as GRC tools are independent from ERP systems (Cangemi, 2008; Mundy \& Owen, 2013). Academic research on the integrated nature of GRC is limited although significant for organizations (Racz, Seufert, \& Weippl, 2010a).

Following the GRC prior research, there are studies with a focus on the application of GRC systems in specific areas and industries. For instance, the case study by Scott and Perry (2012) explores the use of information systems for risk management in the utility sector. The main focus of this study (Scott \& Perry, 2012) is to report on risk management practices and identify related best practices in the energy sector. Similarly, a research by Butler and McGovern (2012) analyses environmental compliance Information Systems and presents a framework for the design of environmental compliance management systems. Other research directions propose a solution to a compliance problem in the area of software licensing (Gangadharan, D'andrea, De Paoli, \& Weiss, 2012) - this approach adopts the Open Digital Rights Language for checking compatibility of free and open source software licenses and mostly focuses on compliance issues.

Furthermore, Hoffmann et al. (2012) suggest the deployment of executable process models by asserting their compliance to a set of rules. This study introduces a semantic annotation approach for process models and the ability to model preconditions and effects of tasks within a process (Hoffmann et al., 2012). On a similar note Strecker et al. (2011) suggest a modelling approach and a process for the assessment of IT risks. Other aspects of GRC systems examined in the literature are the governance of outsourcing relationships (Ali \& Green, 2012) and process management systems requirements to support semantic constraints as well as the criteria that enable integrated compliance support through the entire process lifecycle (Ly, Rinderle-Ma, Göser, \& Dadam, 2012).

While literature on GRC mostly covers the conceptualization and design of integrated GRC solutions, attention has also to be paid to their implementation (Gericke et al., 2009). When reviewing existing GRC literature, the topics about the identification of the "best" risk management approach are often more important than implementation topics such as the identification of activities and resources necessary to rollout a GRC solution to the productive environment (Weber, Bramsemann, \& Heineke, 2004).

The study of Gericke et al. (2009) on GRC implementation puts forward a 'situational implementation method for GRC' that is adaptable to certain project types and requirements of different method users while taking the specifics of the GRC domain. The authors identify the GRC stakeholders and their roles. According to them, the GRC stakeholders are:

(a) Project Manager;

(b) GRC Expert;

(c) Top Management; and

(d) IT Consultant.

The above stakeholder categories are used in this research to identify suitable interviewees at the first stages of the study. The research of Gericke et al. (2009) is one of the few academic perspectives on GRC implementation. To the best of our knowledge, the remainders on GRC implementations are papers from software vendors, whitepapers from consulting companies and articles in online magazines (Racz et al., 2010a). These publications provided secondary data in support of this research as well as confirmation of the outputs; the information provided by these sources has proved to be crucial for developing analyses for GRC IS (Racz et al., 2010a). 
Another aspect of prior studies in the area of GRC systems is the diversity of frameworks around them. For instance, Hayden (2009) and Wiesche et al. (Wiesche, Schermann, \& Krcmar, 2011; Wiesche, Berwing, Schermann, \& Krcmar, 2011) highlight the importance of control methodologies and frameworks for aligning and centralizing the various activities of large organizations, in order to move from traditional organizational GRC silos to an automated and streamlined version of GRC controls (Hayden, 2009; Wiesche et al., 2011). Wiesche et al (Wiesche et al., 2011; Wiesche et al., 2011) focus on the importance of control frameworks before the actual implementation of a GRC tool within the enterprises. Likewise, a model evaluating control frameworks is provided before implementing a GRC software solution (Hayden, 2009). Another control framework for consideration before the implementation of a GRC software is the one presented by Racz et al.(2010a) with the IT GRC Process Model and by Yu et al. (2013) with the IT GRC-based Internal Control Framework (Racz, Seufert, \& Weippl, 2010b; Yu et al., 2013).

In order to support the post-implementation period of GRC solutions, Asprion and Knolmayer (2013) examine the institutional pressures and quality aspects affecting the assimilation of compliance software (Asprion \& Knolmayer, 2013). Key decision points and challenges of GRC for IS and GRC executives were identified in the study of Gozman and Currie (2015), where they focused on key IS capabilities of GRC activities in the financial sector. This research (Gozman \& Currie, 2015) evaluated the maturity of the GRC capabilities and how the activities around GRC are assigned across the enterprise managers.

The study of Nissen and Marekfia (2013) about the GRC management introduces the strategic GRC management requirements and suggests a research agenda for the GRC area. Nissen and Marekfia (2013) in their paper they set a foundation for the future researchers as they focus on listing the areas that should be further investigated in the field of GRC systems management. Our study considered the research directions presented in the Data-Centered Conceptual Reference Model for Strategic GRC-Management (Nissen \& Marekfia, 2014) coupled with the existing frameworks for GRC IS(Spanaki \& Papazafeiropoulou, 2013) and developed a framework for the implementation of the GRC. The theoretical background used was adapted from the enterprise systems adoption lifecycles and the enterprise value drivers. The theoretical aspects will be explained in the following sections as they provide the baseline for designing the research framework and the interviews for this study.

\section{THEORETICAL BACKGROUND}

As it was mentioned in Introduction section, GRC systems are integrated enterprise systems supporting the risk, control and auditing functions inside organizations related with the GRC compliance principles. Therefore, enterprise systems implementation theories are applied for the development of the theoretical framework as the backbone supporting the analysis of the GRC implementation process. The framework is developed from the emerging interview themes from the field study (in research phases 1 and 2 that will be analyzed later) and was supported by foundational enterprise systems implementation theories. Figure 1 illustrates the theoretical background used to support the investigation of the GRC Adoption Lifecycle and Enterprise Value. 


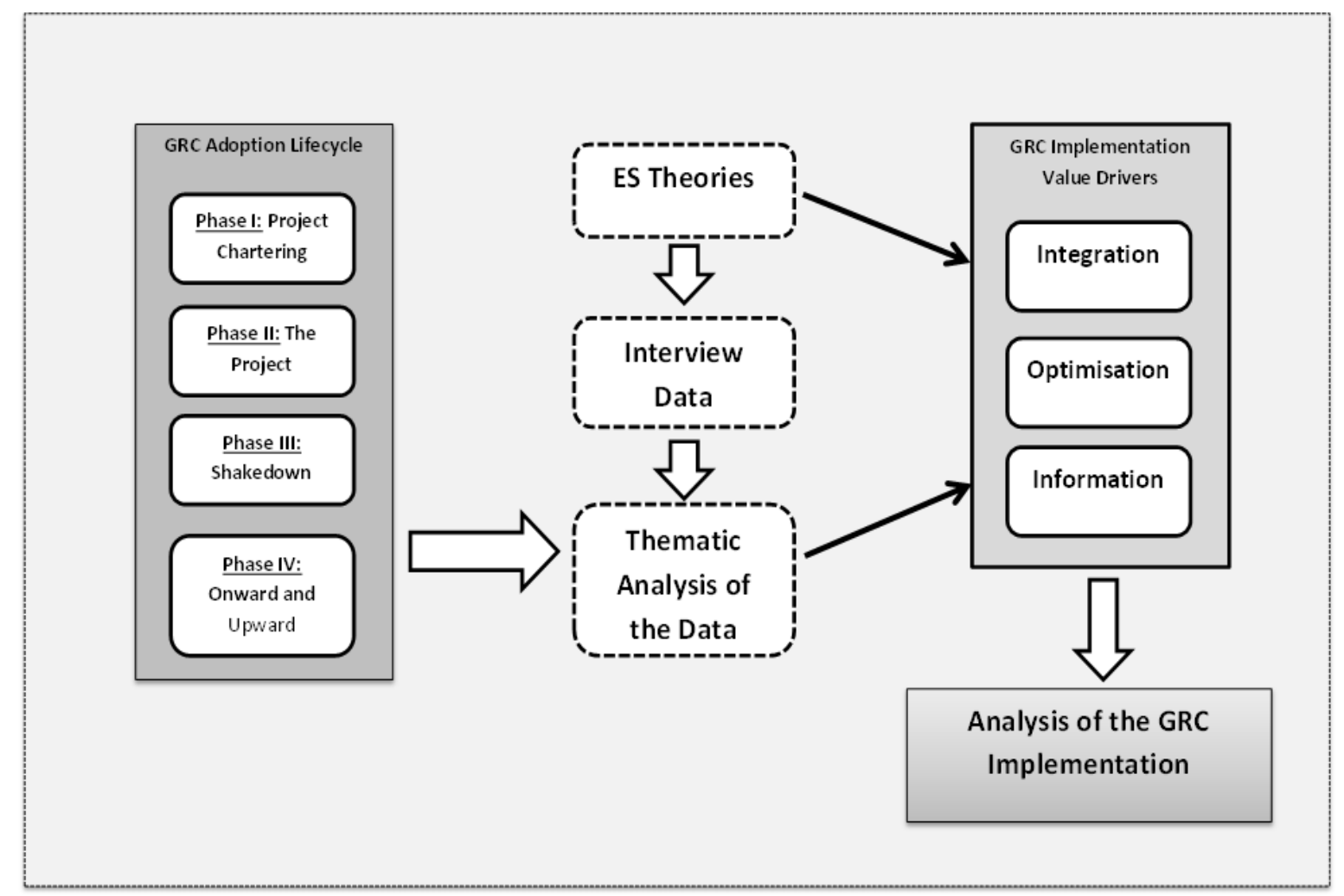

Figure 1. The theoretical model used for the investigation of GRC Adoption Lifecycle and Enterprise Value

\section{Enterprise Systems Adoption Lifecycles}

There are several experience lifecycles proposed by researchers in the literature of enterprise systems implementations (Bancroft, Seip, \& Sprengel, 1998; Markus \& Tanis, 2000; Ross, Weill, \& Robertson, 2006). In most cases, the enterprise system projects share the same implementation process concept (Robey, Ross, \& Boudreau, 2002). The basic difference is in the way researchers divide the implementation process in different steps, the common implementation cycles include five or six (Bancroft et al., 1998; Cooper \& Zmud, 1990; Ross et al., 2006) and four steps (Markus \& Tanis, 2000) respectively. The ES lifecycles support the research for analyzing the ES implementation process and they can assist in identifying similarities and differences among the ES adopters (Soja, Themistocleous, \& Cunha, 2011; Soja, 2006; Themistocleous, Soja, \& da Cunha, 2011).

Among these different experience cycles, our study uses the one developed by Markus and Tanis (2000). We believe this lifecycle suited to the emerging concepts about the implementation phases as these were described throughout the interviews. As shown in Table 1, the enterprise experience lifecycle proposed by Markus and Tanis (2000) includes four implementation phases. This choice is based on the fact that this specific model is easier to use for predicting or explaining an organization's actual enterprise system achievements and successes in a systematic way (Teoh, Tng, \& Pan, 2008). This experience cycle allows crucial implications to be revealed at each stage of the implementation so that we can identify potential problems and provide suggestions to mitigate or resolve issues before they are propagated to the next implementation stage (Teoh et al., 2008). 


\begin{tabular}{|l|l|}
\hline Stage & Description \\
\hline Project Chartering & Decisions defining the business case and solution constraints. \\
\hline Project Configuration & Getting system and end users 'up and running.' \\
\hline Shakedown & Stabilizing, eliminating 'bugs, getting to normal operations \\
\hline Onwards and Upwards & Maintaining system, supporting users, getting results, upgrading \\
\hline
\end{tabular}

Table 1.

The Enterprise Experience Lifecycle (Markus \& Tanis, 2000; Themistocleous, Soja, \& da Cunha,

2011)

\section{Enterprise Value}

Another aspect investigated in this research study is the GRC implementation success. The IS implementation's success is a very important part of the adoption of such solutions. Although several researchers have acknowledged that Enterprise Systems create business value, especially in enabling operational efficiency, not much research has been carried out in the area of ES Success (Bhattacharya \& Seddon, 2011) despite claims from vendors and consultants. Bhattacharya and Seddon (2011) state that there is little research on how such systems can assist the adopting organization to support, execute or even revise the business strategy. However, Bhattacharya et al (2012) developed a model for assessing the business value which enhances the principles of the three 'enterprise value drivers' as these were suggested by Davenport et al. (2004). According to that model, ES can create business value beyond operational efficiency, like in enabling innovation or making strategic decisions (Bhattacharya et al., 2012). Yet, the model focuses more on ERP software and the success of such solutions. Therefore the initial three enterprise value drivers developed by Davenport et al. (2004) are used in this study as they fit to general ES value and can support the research of GRC systems as well. This study investigates the value of GRC IS based on an analysis framework which capitalizes on Davenport's (2004) three drivers.

These drivers are used as cornerstones for the analysis of the GRC IS implementation. The latter are developed in three categories (Davenport et al., 2004) (1) Integration, (2) Optimization, and (3) Information. In more detail, these drivers can be further explained as:

(1) Integrate - This driver focuses on the unified and harmonized data and processes within the unique organizational environment of the enterprises employing enterprise solutions. It also focuses on the business/IT alignment of the processes and the organizational units.

(2) Optimize - This driver focuses on the standardization of the processes with the use of integrated software and how the unique or strategic needs of the enterprises can fit in these systems. It ensures the process flow and the fit with the systems within the organizations.

(3) Informate - This driver focuses on the strategic use of information within the enterprises to transform themselves. The use of information provided by the organizations can assist in transforming the data into context-rich information and knowledge that can support the unique business analysis and decision-making inside the enterprises. 
The drivers are framing the GRC IS implementation analysis by dividing the themes into three categories. However, these drivers-themes are applied through the whole implementation process (lifecycle) and the outputs come from the data analysis of the interviews.

\section{METHODOLOGICAL APPROACH}

The research follows an interpretive philosophical research stance (Klein \& Myers, 1999). This choice is based on the fact that interpretivism allows concepts to emerge from field data (Miles \& Huberman, 1994). Therefore, the study of the GRC Implementation success will allow the concepts/ themes to emerge from the field. Once the concepts emerge they are matched with the adoption lifecycle phases and enterprise value drivers which cannot be separated from the GRC implementation setting. They cannot be separated as they are influencing the whole GRC implementation process and should be considered in order to identify and analyze them effectively.

\section{Research Design}

A field study approach is applied in two phases and aims to gain insight into the implementation phases and drivers influencing the value of the implementation.

- The $1^{\text {st }}$ phase of the investigation involved the development of general knowledge about the GRC IS implementation field. The literature review of the field assisted the identification of the key stakeholders of this process as well as the adoption lifecycle phases and the enterprise value areas that arise from the data.

- The $2^{\text {nd }}$ phase included further investigation on the GRC IS enterprise value areas. The GRC stakeholders were interviewed on the critical areas that can add enterprise value in a GRC implementation and how these influence the success of the GRC IS implementation projects. Throughout the interviewing process there was also a confirmation period of the data after each phase, in order to discuss and validate the findings of each phase. Figure 2 depicts a diagrammatic presentation of the two phases of the study.

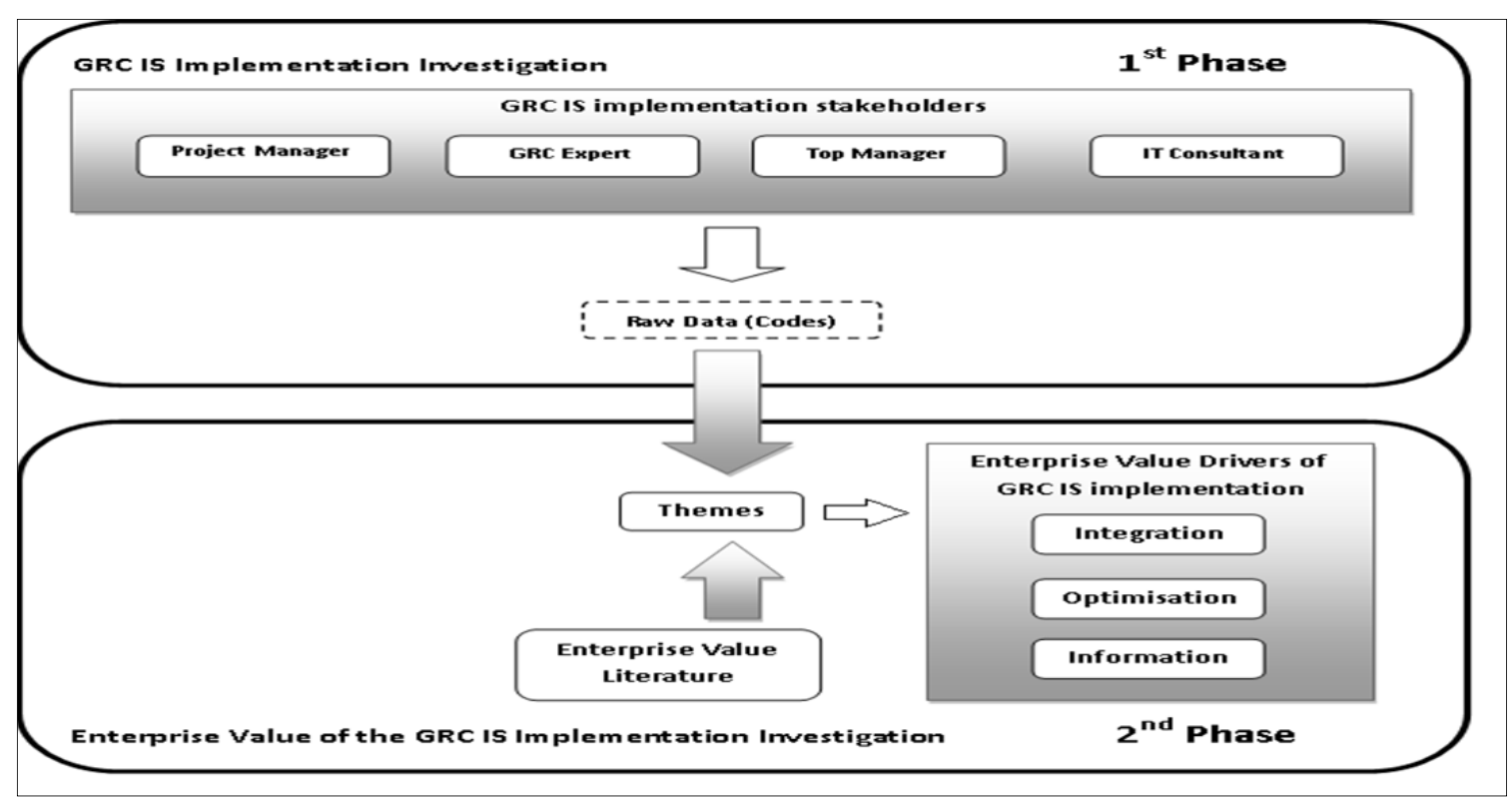

Figure 2. The two phases of the field investigation 
The field study investigation chose different groups of GRC stakeholders and more specifically stakeholders involved in more than three GRC implementation projects worldwide. The names of the interviewees were changed for reasons of confidentiality and anonymity. The interviews had one hour duration and they were recorded and transcribed. The secondary data from the organization's reports as well as from the publicly available resources contributed to the data collected from the interviews at this stage. The method used for the analysis of the semistructured interviews at the first stage was thematic analysis as proposed by Boyatzis (1998) and Braun and Clarke (2006). The identification of the lifecycle phases and the enterprise value drivers for the GRC IS implementation were developed through the coding of the interview data coupled with the literature review of the area.

Observation techniques were used as the evaluation method for the results. The observation as a data collection technique involves noting and recording events, behaviors and artefacts in the social setting chosen for the research study (Marshall \& Rossman, 1999). Observations can provide important information throughout the interviews as it can also provide outputs coming from the body language of the interviewees. Every day world observations as a technique is very common for people, and can support the interpretation of actions and reactions of other members of the society (Adler \& Adler, 1994). The observation technique was used in this study throughout the interviews that took place at the stakeholders' business premises as well as the environment where the stakeholders were participating in a GRC implementation project during the period when the interviews took place. According to Patton (2002), understanding fully the complexities of many situations, direct participation in and observation of the phenomenon of interest may be the best research method. Hence, the study at hand applied observation methods for understanding the GRC setting and evaluating the data from the interviews.

The observations of the GRC environment as well as the whole GRC implementation process provide the required background for the researcher. This background assists in the evaluation of the insights as these were expressed by the interviewees and also assist in the description of the setting. The observational data facilitated the evaluation process of the interviews, where the researcher experiences and observes the GRC implementation process and confirm the validity of the GRC implementation experience as it was described by the interviewees.

\section{The Sampling strategy of the GRC IS implementation interviews}

Sampling is a very complex issue in qualitative research as there are many variations of qualitative sampling described in literature and overlapping of types of sampling (Coyne, 1997). As improved quality of research synthesis is critical it can be achieved through informed decisions about sampling (Suri, 2011). Even though several qualitative researchers have recommended purposeful sampling for qualitative research, the published literature holds sparse discussion on how different strategies for purposeful sampling may be applied to research synthesis (Suri \& Clarke, 2009; Suri, 2011). In primary research, Patton is frequently cited as an authority on the topic of purposeful sampling (Patton, 1991). According to Suri (2011) purposeful sampling requires access to key informants in the field who can help in identifying information-rich cases. Our research used 'mixed purposeful' sampling techniques in order to investigate the GRC implementation in-depth. The mixed purposeful sampling technique combines two or more sampling techniques to adequately address their purpose (Suri \& Clarke, 2009).

Our study employed initially a theory-based sampling approach to identify the interviewees and once the implementation stakeholders were identified, an intensity sampling approach was 
followed in order to collect rich data about the study. Patton (2002) referring to intensity sampling addressed the cases selected for intensity sampling as 'excellent or rich examples of the phenomenon of interest, but not highly unusual cases. These cases manifest sufficient intensity to illuminate the nature of success or failure, but not at the extreme'.

The cases selected for the GRC implementation study were 'key implementation stakeholders' as these were identified by the theoretical background from the study of Gericke et al (2009) and these categories of stakeholders were used to identify the most suitable interviewees. The interviewees were selected based on their experience in GRC implementation projects (the number of projects participated and the number of years in the field of implementations of integrated GRC software developed by large vendors).

The research builds upon the broad understanding and experience of people (stakeholders) involved in GRC IS implementation projects. The qualitative data analysis was conducted in 16 stakeholder interviews and the results of this analysis were confirmed at the end of the each of the two phases.

Sample diversity was achieved through a broad range of roles in the GRC IS implementation projects. In order to introduce diversity and since the different roles within the GRC IS implementation provide different focal points, there were two interviews for each stakeholder group. The stakeholders were working for different implementation projects and they have experience between 5 to 10 years in the implementation of these specific systems.

The companies they work are based in the UK and they have experience in implementation projects worldwide. Table 2 gives further information about each participant. The second phase was also based on field studies. The methodology of the second phase followed the same approach as described for the first phase. The analysis was conducted after each of the two phases of data collection and aimed to get insight about the implementation process of GRC software initiatives.

\begin{tabular}{|c|c|c|c|c|c|}
\hline Participant ID & $\begin{array}{l}\text { Length of } 1^{\text {st }} \\
\text { phase }\end{array}$ & $\begin{array}{l}\text { Length of } 2^{\text {nd }} \\
\text { phase }\end{array}$ & $\begin{array}{l}\text { Length of } \\
\text { confirmation }\end{array}$ & Experience & $\begin{array}{l}\text { Type of company they currently } \\
\text { work }\end{array}$ \\
\hline GRC expert 1 & $1 \mathrm{~h} 25 \mathrm{~min}$ & $1 \mathrm{~h} 25 \mathrm{~min}$ & 0h $28 \mathrm{~min}$ & 8 years & GRC Software vendor \\
\hline GRC expert 2 & $1 \mathrm{~h} 05 \mathrm{~min}$ & $1 \mathrm{~h} 45 \mathrm{~min}$ & 0h 15 min & 9 years & GRC Consulting Company \\
\hline $\begin{array}{ll}\text { GRC } & \text { Project } \\
\text { Manager } 1 & \\
\end{array}$ & 1h 40 min & 1h $40 \mathrm{~min}$ & Oh $22 \mathrm{~min}$ & 10 years & GRC Consulting Company \\
\hline $\begin{array}{ll}\text { GRC } & \text { Project } \\
\text { Manager 2 } & \\
\end{array}$ & 1h 55 min & 1h 15 min & 0h 32 min & 7 years & $\begin{array}{l}\text { Company that have already } \\
\text { implemented GRC }\end{array}$ \\
\hline Top Manager 1 & 0h 45min & 0h 45min & 0h $16 \mathrm{~min}$ & 6 years & $\begin{array}{l}\text { Company in the process of GRC } \\
\text { implementation }\end{array}$ \\
\hline Top Manager 2 & 0h 35min & 1h 05 min & 0h 23min & 5 years & $\begin{array}{l}\text { Company that have already } \\
\text { implemented GRC }\end{array}$ \\
\hline IT Consultant 1 & 1h 45 min & 1h $45 \min$ & 0h $27 \mathrm{~min}$ & 5 years & GRC Software vendor \\
\hline IT Consultant 2 & 1h $48 \mathrm{~min}$ & 1h 36 min & 0h $21 \mathrm{~min}$ & 5.5 years & GRC Consulting Company \\
\hline
\end{tabular}

Table 2. $\quad$ Project roles and Interviewees of the $1^{\text {st }}$ and $2^{\text {nd }}$ phase 
The stakeholder categories as these were summarized above include a project team, which is headed by a project manager. The project manager coordinates the project and gives directions for the whole implementation process and the activities involved; therefore, the project management role is crucial for GRC implementations. The GRC expert specializes in all the areas of the GRC IS. The support provided is within the scope of the expertise for the processes implemented. The expert is also responsible for the integration of the relevant business processes within the system. The top manager is responsible for the development of the project strategy; and to support the strategy that will be followed during the whole project. The IT consultants are responsible for the integration of the system with the organizational environment of the enterprise. Moreover, they provide training and directions to the IT unit of the enterprise for using the newly implemented system.

\section{THE GRC IS ADOPTION LIFECYCLE}

The GRC IS implementation process was divided by the interviewees in four implementation phases:

(a) The preparation period prior the implementation;

(b) The period when the GRC project is actually launched;,

(c) The period when the GRC system is implemented in the organization; and

(d) The post-implementation period.

These phases were identified by the key stakeholders interviewed in the $1^{\text {st }}$ phase of the field investigation, and more specifications about each of these were given to support the description of each of these phases.

The preparation period prior to the implementation, as described by the interviewees, included organizational decisions about the implementation of a tool for controlling and monitoring their business and financial processes. The main goals and objectives should be set from this initial phase, as well as the requirements for such an implementation, from an organizational and technical perspective. The key stakeholders should take a basic role at this stage, as they need to consider the critical success factors and the problems of such a project, in order to be prepared for the successful implementation.

The period when the project is actually launched was described by the interviews as crucial. The project stakeholders take their actual roles within the project under strong project management supervision. The project management support was highlighted as a necessary aspect of this period, as all stakeholders should work together without any conflicts, despite different priorities and interests for the new system.

The period when the system is implemented included the use of the system at its initial stages and the training of the people involved in the operating and controlling processes inside the organization. At this period, the IT team of the organization plays an important role as the team members should get involved with the system operations and they should be well trained with the help of the consultants. At this stage, the IT team gets the knowledge of the system in order to work afterwards without relying on external consultants, which would introduce greater risks.

The post-implementation period was described as the normal routine after the system adoption. The people inside the organization are familiar with the system; the IT team is upgrading the system with new versions and patches, as they are experienced in solving any occurring issues with the system. 
This implementation lifecycle for the GRC fits the implementation lifecycle of ES as Markus and Tanis (2000) described it. The authors developed the ES experience lifecycle in four phases: a) project chartering phase, b) project phase (configure and rollout), c) shakedown phase, d) onward and upward phase. These four phases of the ES experience lifecycle are matched to the GRC experience lifecycle and will support the analysis framework of GRC for the $2^{\text {nd }}$ phase. This experience lifecycle will be used in the following section to provide a backbone for the further investigation of the GRC implementation process of the $2^{\text {nd }}$ phase.

\section{THE ENTERPRISE VALUE DRIVERS OF GRC IS PROJECTS}

As it was developed in the previous sections the investigation focuses on identifying the enterprise value areas that should be analyzed throughout the GRC IS implementation for achieving a successful outcome. Therefore, our study includes identification of the enterprise value areas of the implementation projects in general for a first instance as an output of the first investigation phase. The enterprise value drivers-themes identified in the first phase were discussed and enhanced with a more specific analysis for the GRC IS implementation in the second phase.

The data from the interviews were analyzed through three theory-driven dimensions (integration, optimization, and information). The themes include the key areas discussed by the stakeholders for each phase as they were interviewed about the GRC implementation process. The GRC implementation process discussion was divided in three core areas- themes (integration, optimization, information) as these were identified by the first field investigation phase coupled with the theoretical background about IS success.

The data collection of this field investigation came with three areas of data as discussed with the interviewees. These three areas-themes are presented in the tables below (Table 3, 4, 5).

\begin{tabular}{|c|c|c|}
\hline \multirow{5}{*}{ 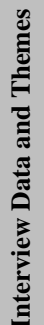 } & Raw Data (Codes) & Themes \\
\hline & The view for an integrated GRC tool is understood and agreed by the organization stakeholders. & \multirow{4}{*}{$\begin{array}{l}\text { Theme 1: } \\
\text { Integration }\end{array}$} \\
\hline & There is a need for GRC software that aligns business processes with the current control frameworks. & \\
\hline & The strategic fit between people and GRC technology in the organizational setting is required. & \\
\hline & The GRC technological solutions can be embedded to the current enterprise systems within the organization. & \\
\hline
\end{tabular}

Table 3. Interview Data about the Integration Theme

\begin{tabular}{|c|c|c|}
\hline \multirow{5}{*}{ 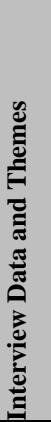 } & Raw Data (Codes) & Themes \\
\hline & The organization supports proactive ways in terms of user access, process automation, and improving processes. & \multirow{4}{*}{$\begin{array}{l}\text { Theme 2: } \\
\text { Optimization }\end{array}$} \\
\hline & $\begin{array}{l}\text { The GRC system implementation follows with 'end-to-end' optimized processes when the systems are up and } \\
\text { running. }\end{array}$ & \\
\hline & $\begin{array}{l}\text { The stability of the GRC system functionality is through the elimination of the problems of the GRC system, } \\
\text { arising after the implementation }\end{array}$ & \\
\hline & $\begin{array}{l}\text { The new updated versions of the GRC system should support a stabilized and optimized GRC environment } \\
\text { through their functionality }\end{array}$ & \\
\hline
\end{tabular}

Table 4. Interview Data about the Optimization Theme 


\begin{tabular}{|c|c|c|}
\hline \multirow{5}{*}{ 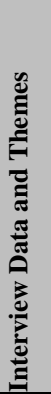 } & Raw Data (Codes) & Themes \\
\hline & $\begin{array}{l}\text { The organization already follows a control framework and seeks for a GRC technology to automate these } \\
\text { controls. }\end{array}$ & \multirow{4}{*}{$\begin{array}{l}\text { Theme 3: } \\
\text { Information }\end{array}$} \\
\hline & The information from the control framework has to be plugged in the new technological solutions. & \\
\hline & $\begin{array}{l}\text { The data about information risk, user provisioning and business process ownership are available from the IT } \\
\text { basis team of the organization }\end{array}$ & \\
\hline & The organization possess the information about what can be improved can help emerging issues in-house. & \\
\hline
\end{tabular}

Table 5.

Interview Data about the Information Theme

\section{A COMPREHENSIVE ANALYSIS AND DISCUSSION}

This section further discusses the data gathered in the field studies (first and second) and explains how the analysis of the three value areas- themes that arose from stakeholder discussion can assist in understanding the GRC IS implementation and how it can add value to the GRC landscape of the enterprises if successful. To provide a better understanding of the methodological approach taken in this study, Table 6 illustrates a summary of the main results.

\begin{tabular}{|c|c|c|c|}
\hline & $\begin{array}{l}\text { Driver 1: } \\
\text { Integration }\end{array}$ & $\begin{array}{l}\text { Driver 2: } \\
\text { Optimisation }\end{array}$ & $\begin{array}{l}\text { Driver 3: } \\
\text { Information }\end{array}$ \\
\hline $\begin{array}{l}\text { Phase I: } \\
\text { Project } \\
\text { Chartering }\end{array}$ & $\begin{array}{l}\text { Organizations have a clear } \\
\text { view for an integrated GRC } \\
\text { system }\end{array}$ & $\begin{array}{l}\text { The organizations are concerned about } \\
\text { proactive ways in terms of user access, } \\
\text { process automation and improving } \\
\text { processes }\end{array}$ & $\begin{array}{l}\text { Organizations seek for a GRC tool to } \\
\text { assist the already existing control } \\
\text { frameworks }\end{array}$ \\
\hline $\begin{array}{l}\text { Phase II: } \\
\text { The project } \\
\text { (configure and } \\
\text { rollout) }\end{array}$ & $\begin{array}{l}\text { The strategic fit between the } \\
\text { system and the business } \\
\text { processes }\end{array}$ & $\begin{array}{l}\text { The 'end to end' optimisation of the } \\
\text { system processes within the } \\
\text { organisational environment }\end{array}$ & $\begin{array}{l}\text { The integration of the information from } \\
\text { the control frameworks in the GRC } \\
\text { system }\end{array}$ \\
\hline $\begin{array}{l}\text { Phase III: } \\
\text { Shakedown }\end{array}$ & $\begin{array}{l}\text { The combination of people and } \\
\text { technology in a strategically } \\
\text { aligned GRC environment }\end{array}$ & $\begin{array}{l}\text { The elimination of the occurring system } \\
\text { problems, while stabilising its } \\
\text { functionality }\end{array}$ & $\begin{array}{l}\text { The availability of the data about } \\
\text { information risk, user provisioning and } \\
\text { business process ownership }\end{array}$ \\
\hline $\begin{array}{l}\text { Phase IV: } \\
\text { Onward and } \\
\text { Upward }\end{array}$ & $\begin{array}{l}\text { The new technological } \\
\text { solutions can be embedded to } \\
\text { the current systems }\end{array}$ & $\begin{array}{l}\text { The new versions of the system function } \\
\text { can stabilise their functionality }\end{array}$ & $\begin{array}{l}\text { Information can be provided about } \\
\text { controlling and audit improvements and } \\
\text { emerging issues regarding the system }\end{array}$ \\
\hline
\end{tabular}

Table 6. Summarizing table of the GRC Adoption Lifecycle and Enterprise Value Analysis (Spanaki \& Papazafeiropoulou, 2013)

\section{Enterprise Value Driver 1: the GRC IS Integration}

The GRC systems, as these are developed within the organizational environment, are highly integrated solutions. Due to that integration, the enterprise can have a full view of the business processes to control and operate these systems (Rasmussen, 2009). The integration aspect of GRC tools should be established for considering the implementation process as a successful one 
(Nissen \& Marekfia, 2014). Racz, et al (2010b) divide the GRC integration in two levels: horizontal and vertical. The horizontal level refers to the integration of the three disciplines (Governance, Risk and Compliance) together and the vertical level refers to the integration of the GRC system with the business processes.

There is also another grouping for the GRC integration by Nissen and Marekfia (2014) which includes four categories:

(a) Textual integration

(b) Operational processes integration

(c) Methodological integration

(d) IT integration

The interview themes include both types of GRC integration, but mostly the integration of the GRC system with the business processes. The thematic analysis came out to indicate the three themes coming from the data in combination with the ES theories. The four areas- codes developed through the thematic analysis of the data, which included in the 'integration' dimension, are described in Table 3.

One of the GRC system requirements is that all the enterprise systems are integrated to the GRC environment with the purpose to provide a clear picture of the risks inside the organization. The clear view of the organizational environment can be also considered when analyzing the optimization dimension of the GRC systems. However, the integration of the GRC system with the business processes and other enterprise systems used in the current organizational environment is related to the vision of the enterprise architecture. Mitchell's (2007) approach supports the enterprise architecture, while the capability model is suggested as the roadmap to develop the integrated view of the GRC environment. Therefore, when analyzing the GRC implementation process, as also supported by the literature and the interview dataset (themes), integration is one of the important requirements for a successful implementation that can add value to the organization.

The integration dimension for a GRC implementation describes the whole view of the enterprise for an integrated GRC environment. This integrated GRC environment comprises a common understanding of the GRC processes from the key stakeholders involved. Hence, the whole organization has to work with the new integrated GRC tool that monitors and analyses the risks in the systems, although each of the stakeholders may have different interests for each business process.

Another theme discussed during the interviews was the strategic fit between the GRC system and the business processes - also included in the vertical integration (Racz et al., 2010b) and operational process integration (Nissen \& Marekfia, 2014; Racz et al., 2010b). According to this type of integration the system should standardize and embed all the business processes in order for the system to deliver the best business value for the enterprise. If these are followed, the controlling and the financial transactions will be automatically processed and the goal of streamlined transaction processes will be achieved.

In the operational process integration, the combination of people and technology in a strategically aligned GRC environment should be considered. The stakeholders should follow the GRC disciplines inside the organization as well as the roles to be successfully assigned; who controls their content and who approves their risks needs to be defined. All systems related to GRC are connected to it and the user-access and authorization levels should be defined. If this fit is achieved from the start, the GRC integration will add value to the whole implementation process. 
The IT integration was also supported by the interview themes, especially in the later stages of the implementation. As already discussed, the new technological solutions have to be embedded to the current systems, especially at later stages. At that point, the GRC tool is already implemented and integrated with the business and organizational processes, and the operational stability is ensuring the integration of the system from an organizational perspective. However, the IT integration of the system should also be assured as the system will control and help the IS auditing process. For these reasons, the GRC tool should provide integration with all the systems used in the organizational environment and the updates of the system - that will be developed in the future- should ensure that part of the integration.

\section{Enterprise Value Driver 2: The GRC IS optimization}

The optimization dimension in an enterprise system implementation and more specifically the GRC implementation focuses mostly on a streamlined automated controlling environment, where operations are not facing obstacles by access control functions when required. Previous research in GRC addresses the optimization dimension of the GRC tools by providing frameworks and strategies to develop optimization plans for the GRC solutions of the organizations. There are a few studies that provide insight to the practices and activities that should be adopted in order to develop the optimization strategy of the GRC tools; these studies suggest a framework for 'principled performance' as a roadmap for the optimization of a GRC environment (Mitchell, 2007). Other studies in the area provide solutions and suggestions in the same direction, analyzing steps and processes in Models and Frameworks as a guide to drive better operational performance with the use of GRC tools (Nissen \& Marekfia, 2014). The dataset from the interviews included discussions about the following four areas regarding the GRC optimization theme, as these are described in Table 4 above.

The optimization area of the GRC implementation involves proactive ways in terms of user access, process automation, and improving processes. In other words, the enterprises try to prevent the risk of not having a stabilized GRC environment with the use of optimized GRC systems. Following this aim, the key stakeholders are concerned about optimized and standardized processes. Therefore the organization needs a tool for monitoring and analyzing the business processes in order to prevent any possible risk related to the GRC principles. The accountability of IS plays an important role in the organizational development, one of the basic business goals is to continuously control and monitor the systems to assure a proactive attitude to risk, but also a reactive as well; in case the risk was not forecasted.

A basic challenge the implementation team has to overcome is to achieve this level of optimization when all teams (finance team, IT team etc) work together to support the implementation project as well as to communicate and fully understand the project objectives. The necessity of optimized GRC systems with stable functionality can also be crucial for the system optimization during and after the implementation process. In that part, the optimization dimension includes the 'end to end' optimization of the system processes within the organizational environment.

The system functionality has to be established in the implementation process; for that reason it can be stabilized via the elimination of the occurring system problems. This can happen when the system is up and running with the users having the access they need and the systems are agile, enabling them to continually adjust to any change of roles and authorizations.

The systems have to introduce new controls at a high frequency following the latest controlling and IT auditing service trends. The new versions of the system functions can stabilize 
their functionality. The functionality of the GRC system, which is highly related to the optimization dimension, should also be included in the new versions of the system functions, in order to stabilize a functional GRC environment.

\section{Enterprise Value Driver 3: The GRC IS information}

The information dimension is very crucial for the GRC implementation process as this will provide all the setting up instructions and frameworks for the project plan. The information will provide the ground in building the suitable GRC environment for the organization implementing such a system, according to the risk appetite of the enterprise. Information is required not only for the implementation period, but also for the post-implementation period, as the data and information the system is operating will be used for risk reports and will inform the organization for further decisions.

The principles of GRC are not new; what is introduced with the GRC integrated approach always existed for every well-run company, but they were applied in manual or partially automated ways. Goals as identifying risks, financial reporting and complying with the regulations, were always parts of a company's obligations. With regards to information, the organization had to provide it to the stakeholders and the government. The urgency of various issues within the last decade forced companies to adopt a holistic approach to ' $G$ ', ' $R$ ' and ' $C$ ' principles for their best performance and their strategic advantage. The rise of compliance regulations, coupled with the increasing need of sensitive data security are some of the challenges enterprises are facing nowadays. The organizations need a total solution to inform and identify risks and have the required information in place to follow the existing compliance regulations from external or internal pressures.

The discussion with the interviewees provided data mostly about the information associated to the implementation of the GRC. In addition, the interview dataset provided insight on how the information dimension can exist in the post-implementation period for sustaining a successful GRC environment inside the organization. The themes produced for the information dimension are described in Table 5.

The control framework already exists in the organization before the implementation; however, the stakeholders seek an integrated GRC technology for these controls. That interest for a GRC tool to assist the already existing control frameworks can be observed during the whole implementation lifecycle also for the post-implementation period. The organization operated manually or with partially automated solutions following the GRC principles; for that reason key stakeholders focus on continuous development of a total solution to identify and inform the organization about risks and to comply with the internal and external standards. The GRC implementation is presented as a solution to assist the existing frameworks of control and risk management in a more holistic way. Therefore the existing frameworks should be embedded in the new solution to achieve the best performance through the information about the previous organizational environment.

The information from the control framework needs to be integrated in the new technological solutions (GRC tools) throughout the implementation process. This can be achieved if the organization provides full information about improving functions such as: Information Risk, user provisioning and business process ownership. Information also should be provided regarding areas of the roles that would be assigned and what systems will be connected. The project team needs full information about the existing systems and their users. The project team also has to train people within the company about the system for understanding how it 
works. Following the same aim, the key stakeholders should have a common understanding of the ongoing process introduced by GRC - 'Clean - Stay clean- Monitor'

All information in the systems can be accessed and viewed quickly and easily. For successful GRC implementation, information should be provided to the implementation team and the key stakeholders in all steps of the implementation. All data and information required to set up the system should be available especially in the shakedown phase of the implementation where the stabilization of the system is secured. The availability of data about information risk, user provisioning and business process ownership from the IT basis team is a basic requirement at this stage.

\section{CONCLUSION}

The purpose of this paper is to develop a framework for the analysis of GRC IS implementation combining two theoretical streams (the adoption lifecycles and the enterprise value drivers) drawing from the dataset. The interviews were analyzed through thematic analysis and the key areas were discussed and confirmed by the stakeholders. The field study revealed that the expected benefits from a GRC IS implementation could be achieved if the implementation process is successful. The implementation can result in valuable outcomes for the whole project, if the factors driving to the success of the GRC IS within the organization are considered beforehand.

Through the investigation of successful GRC IS implementation projects and with the help of enterprise system theories, this study presented a categorization of the critical drivers for the success of the GRC IS implementation projects. The study has shown that analysis of the GRC IS implementation process can identify the value drivers and the results can be used for achieving successful implementation plans for the GRC IS strategy. This categorization and synthesis of value drivers with GRC implementation phases is unique. In the current literature there is a general description of value drivers in ES projects or GRC projects in particular but there is no analysis of how this value is achieved in each one of the project phases. This study contributes to the literature of ES implementation in general and GRS IS implementation in particular by providing details of value creation within each of the implementation phases, as presented in the previous section of this paper (Comprehensive analysis and discussion). The results of this study can be used in the future by researchers in the implementation of GRC systems but also other ES such as Customer Relationship Management (CRM) or Supply Chain Management (SCM) systems. Table 6 can be used as a guideline for other studies where the implementation of company-wide systems is examined.

In summary, from a theoretical perspective, the research contributes to the knowledge about GRC systems and their implementation within enterprises, as an attempt to gain a better insight of this newly developed area of enterprise systems. Secondly, it addresses missing parts of the existing GRC IS implementation literature by focusing on their enterprise value drivers.

In terms of practical contribution, the value drivers and the relevant analysis can help stakeholders within GRC IS implementation projects to make the right decisions when it comes to the integration, optimization and the information needs of the project. The research gives an insight of the implementation process of these systems by focusing on enterprise value areas that should receive more attention from the stakeholders throughout the entire implementation process. Our analysis can help enterprises follow a risk-averse GRC plan and avoid further risks in post-implementation phases. Furthermore, the framework developed in this research can help 
the design of GRC strategies for organizations not yet involved in GRC IS use but willing to consider GRC practices for gaining competitive advantage.

The main limitation of the study is associated with the number of participants. This limitation was alleviated to a certain degree by the participants' vast experience in GRC projects in various organizational and geographical settings. Future research in the field can use this analysis of the GRC implementation and investigate further ways of improving and enhancing the enterprise performance. The use of multiple case studies or stakeholder analysis can be used to achieve this research goal. Another future research project could be the identification of possible problem areas of the GRC application within each one of the implementation phases.

\section{AUTHOR BIOS}

Konstantina Spanaki is a Research Associate in the Department of Innovation and Entrepreneurship, Imperial College London. Her main research interests lie within the area of Information Systems, with a particular focus on IS adoption, business integration and information management intelligence. She received her Ph.D. in Information Systems from Brunel University London and a M.Sc. in Information Systems and Management from Warwick Business School, UK. She also holds a B.Sc. (Hons) in Business Administration (major: Information Systems Management) from Athens University of Economics and Business, Greece.

Anastasia Papazafeiropoulou is a senior lecturer in the Department of Computer Science Brunel University, UK. She has been involved in a number of European and UK funded research projects with emphasis on electronic commerce and small and medium size enterprises (SMEs). She teaches information systems management and business integration at the postgraduate level. She also supervises researchers in the field of technology adoption by organizations with special interest in developing countries. She has 10 years of research experience on the study of diffusion and adoption of electronic commerce, broadband Internet, Enterprise Recourse Planning Systems (ERPs), Customer Relationship Management systems (CRMs), IP-telephony and mobile TV.

\section{ACKNOWLEDGEMENTS}

The authors would like to thank the Editor and the anonymous reviewers for their constructive comments and suggestions for improvement on the earlier versions of this paper. Konstantina Spanaki would like also to acknowledge Grant EP/ K039504/1 from Engineering and Physical Sciences Research Council (EPSRC) which funded part of this research

\section{REFERENCES}

Adler, P. A., \& Adler, P. (1994). Observational techniques. Handbook of Qualitative Research, 40

Ali, S., \& Green, P. (2012). Effective information technology (IT) governance mechanisms: An IT outsourcing perspective. Information Systems Frontiers, 14(2), 179-193.

Asprion, P. M., \& Knolmayer, G. F. (2013). Assimilation of compliance software in highly regulated industries: An empirical multitheoretical investigation. System Sciences (HICSS), 2013 46th Hawaii International Conference On, 4405-4414.

Bancroft, N., Seip, H., \& Sprengel, A. (1998). Implementing SAP R/3: How to introduce a large system into a large organization. Greenwich, CT: Manning Publication Co. 
Bhattacharya, P. J., \& Seddon, P. B. (2011). Going beyond operations with enterprise systems. ACIS 2011 Proceedings,

Bhattacharya, P. J., Seddon, P. B., \& Scheepers, R. (2012). Enterprise systems for innovation in products and processes: Beyond operational efficiency. ACIS 2012: Location, Location, Location: Proceedings of the 23rd Australasian Conference on Information Systems 2012, 111.

Boyatzis, R. E. (1998). Transforming qualitative information: Thematic analysis and code development. Thousand Oaks, CA, US: Sage Publications, Inc.

Braun, V., \& Clarke, V. (2006). Using thematic analysis in psychology. Qualitative Research in Psychology, 3(2), 77-101.

Butler, T., \& McGovern, D. (2012). A conceptual model and IS framework for the design and adoption of environmental compliance management systems. Information Systems Frontiers, 14(2), 221-235.

Cangemi, M. P. (2008). The controls challenge. Bank Accounting \& Finance, 21(5), 43-52.

Cooper, R. B., \& Zmud, R. W. (1990). Information technology implementation research: A technological diffusion approach. Management Science, 36(2), 123-139.

Coyne, I. T. (1997). Sampling in qualitative research. purposeful and theoretical sampling; merging or clear boundaries? Journal of Advanced Nursing, 26(3), 623-630.

Davenport, T. H., Harris, J. G., \& Cantrell, S. (2004). Enterprise systems and ongoing process change. Business Process Management Journal, 10(1), 16-26. doi:doi:10.1108/14637150410518301"

Frigo, M. L., \& Anderson, R. J. (2009). A strategic framework for governance, risk, and compliance. Institute of Management Accountants.,

Gangadharan, G., D’andrea, V., De Paoli, S., \& Weiss, M. (2012). Managing license compliance in free and open source software development. Information Systems Frontiers, 14(2), 143154.

Gericke, A., Fill, H., Karagiannis, D., \& Winter, R. (2009). Situational method engineering for governance, risk and compliance information systems. Philadelphia, Pennsylvania: ACM.

Gozman, D., \& Currie, W. (2015). Managing governance, risk, and compliance for post-crisis regulatory change: A model of IS capabilities for financial organizations. System Sciences (HICSS), 2015 48th Hawaii International Conference On, 4661-4670.

Hayden, L. (2009). Designing common control frameworks: A model for evaluating information technology governance, risk, and compliance control rationalization strategies. Information Security Journal: A Global Perspective, 18(6), 297-305.

Hoffmann, J., Weber, I., \& Governatori, G. (2012). On compliance checking for clausal constraints in annotated process models. Information Systems Frontiers, 14(2), 155-177.

Klein, H. K., \& Myers, M. D. (1999). A set of principles for conducting and evaluating interpretive field studies in information systems. MIS Quarterly: Management Information Systems, 23(1), 67-94.

Lee, R. (1998). An enterprise decision framework for information system selection. Information Systems Management, 15(4)

Leishman, M., Brouwers, P., \& Farineau, D. (2009). Continuous auditing/continuous Monitoring-Using technology to drive value by managing risk and improving performance. KPMG International, 
Ly, L. T., Rinderle-Ma, S., Göser, K., \& Dadam, P. (2012). On enabling integrated process compliance with semantic constraints in process management systems. Information Systems Frontiers, 14(2), 195-219.

Markus, M. L., \& Tanis, C. (2000). The enterprise systems experience - from adoption to success. In R. W. Zmud (Ed.), Framing the domains of IT management: Projecting the future through the past (1st ed., pp. 173-207) Pinnaflex Educational Resources.

Marshall, C., \& Rossman, G. B. (1999). Designing qualitative research. Sage Publications.

Maurizio, A., Girolami, L., \& Jones, P. (2007). EAI and SOA: Factors and methods influencing the integration of multiple ERP systems (in an SAP environment) to comply with the sarbanes-oxley act. Journal of Enterprise Information Management, 20(1), 14-31. doi:10.1108/17410390710717110

Miles, M. B., \& Huberman, A. M. (1994). Qualitative data analysis: An expanded sourcebook (2nd ed.). Thousand Oaks ; London: Sage.

Mitchell, S. L. (2007). GRC360: A framework to help organisations drive principled performance. International Journal of Disclosure and Governance, 4(4), 279-296. doi:doi:10.1057/palgrave.jdg.2050066"

Mundy, J., \& Owen, C. A. (2013). The use of an ERP system to facilitate regulatory compliance. Information Systems Management, 30(3), 182-197.

Nissen, V., \& Marekfia, W. (2013). Towards a research agenda for strategic governance, risk and compliance (GRC) management. Business Informatics (CBI), 2013 IEEE 15th Conference On, 1-6.

Nissen, V., \& Marekfia, W. (2014). The development of a data-centred conceptual reference model for strategic GRC-management. Journal of Service Science and Management, 7(02), 63.

Papazafeiropoulou, A., \& Spanaki, K. (2015). Understanding governance, risk and compliance information systems (GRC IS): The experts view. Information Systems Frontiers, , 1-13.

Patton, M. Q. (1991). Towards utility in reviews of multivocal literatures. Review of Educational Research, , 287-292.

Patton, M. Q. (2002). Designing qualitative studies. Qualitative Research and Evaluation Methods, 3, 230-246.

Racz, N., Seufert, A., \& Weippl, E. (2010a). A frame of reference for research of integrated governance, risk \& compliance (GRC). Proceedings of IFIP CMS 2010,

Racz, N., Seufert, A., \& Weippl, E. (2010b). A process model for integrated IT governance, risk, and compliance management. Proceedings of the Ninth Baltic Conference on Databases and Information Systems (DB\{ $\mid \&\} I S$ 2010), 155-170.

Rasmussen, M. (2009). Foundations of GRC: Establishing an enterprise view of risk \& compliance. Corporate Integrity, Governance, Risk Manager and Compliance Research,

Robey, D., Ross, J. W., \& Boudreau, M. (2002). Learning to implement enterprise systems: An exploratory study of the dialectics of change. J.Manage.Inf.Syst., 19(1), 17-46.

Ross, J. W., Weill, P., \& Robertson, D. C. (2006). Enterprise architecture as strategy: Creating a foundation for business execution Harvard Business School Press.

Scott, S., \& Perry, N. (2012). The enactment of risk categories: The role of information systems in organizing and re-organizing risk management practices in the energy industry. Information Systems Frontiers, 14(2), 125-141. 
Soja, P., Themistocleous, M., \& Cunha, P. R. (2011). Playing catch up: How different is large scale enterprise systems implementation in transition countries and organizations? System Sciences (HICSS), 2011 44th Hawaii International Conference On, 1-10.

Soja, P. (2006). Success factors in ERP systems implementations: Lessons from practice. Journal of Enterprise Information Management, 19(4), 418-433. doi:doi:10.1108/17410390610678331"

Spanaki, K., \& Papazafeiropoulou, A. (2013). Analysing the governance, risk and compliance (grc) implementation process: Primary insights. European Conference on Information Systems (ECIS), Utrecht,Neatherlands.

Strecker, S., Heise, D., \& Frank, U. (2011). RiskM: A multi-perspective modeling method for IT risk assessment. Information Systems Frontiers, 13(4), 595-611.

Suri, H. (2011). Purposeful sampling in qualitative research synthesis. Qualitative Research Journal, 11(2), 63-75.

Suri, H., \& Clarke, D. (2009). Advancements in research synthesis methods: From a methodologically inclusive perspective. Review of Educational Research, 79(1), 395-430.

Teoh, S., Tng, Q., \& Pan, S. (2008). The emergence of dynamic capabilities from a SMEenterprise system upgrade. 16th European Conference on Information Systems,

Themistocleous, M., Soja, P., \& da Cunha, P. R. (2011). The same, but different: Enterprise systems adoption lifecycles in transition economies. Information Systems Management, 28(3), 223-239.

Weber, J., Bramsemann, U., \& Heineke, C. (2004). Wertorientierte unternehmenssteuerung: Konzepte - implementierung - praxisstatements (transl. value-based management: Concepts implementation - practical experiences). (). Wiesbaden: Gabler.

Wiesche, M., Berwing, C., Schermann, M., \& Krcmar, H. (2011). Patterns for understanding control requirements for information systems for governance, risk management, and compliance (GRC IS). Advanced Information Systems Engineering Workshops, 208-217.

Wiesche, M., Schermann, M., \& Krcmar, H. (2011). Understanding the role of information technology for organizational control design: Risk control as new control mechanism. Governance and sustainability in information systems. managing the transfer and diffusion of IT (pp. 135-152) Springer.

Yu, Y. R., Seo, S. C., \& Kim, B. K. (2013). IT GRC-based IT internal control framework. Advanced Communication Technology (ICACT), 2013 15th International Conference On, 382-385. 